\title{
Modelagem de uma Planta Heliotérmica CSP com Armazenamento de Calor e Hibridização para Petrolina
}

\author{
Modeling of a CSP Heliothermic Plant with Heat Storage and Hybridization for Petrolina
}

Anthyê Halerrandro ${ }^{1}$ orcid.org/0000-0002-1995-2197

Alcides Codeceira Neto ${ }^{1}$ (Dorcid.org/0000-0001-6529-4925

${ }^{1}$ Escola Politécnica de Pernambuco, Pós-graduação em Energias Solar e Eólica,
Universidade de Pernambuco, Pernambuco, Brasil.

E-mail do autor principal: Anthyê Halerrandro anthyesilva@gmail.com

\section{RESUMO}

No Brasil, uma região conhecida como semiárido nordestino possui elevado potencial para implantação de uma usina heliotérmica. Uma das cidades que fazem parte dessa região é Petrolina. Em Petrolina, a implantação de uma usina heliotérmica de tecnologia cilindro-parabólico pode ser vista como uma tentativa de inserir e consolidar essa tecnologia na matriz energética brasileira. Este trabalho visa modelar e simular uma planta heliotérmica híbrida e com armazenamento de calor, de forma a explorar o potencial de energia solar irradiada nessa região para transformá-la em energia elétrica. Utilizando o software SAM, são obtidos os dados de irradiação solar de Petrolina, realizado a simulação e a análise de resultados técnico-econômicos. Entre os resultados obtidos se destacam o fator de capacidade de $77,5 \%$ e a geração de energia elétrica de336.235.872,00 kWh, ambos dados do primeiro ano da análise. Os métodos de análises de investimento utilizados para o estudo da viabilidade foram a taxa interna de retorno e o valor presente líquido, ambos favoráveis a implantação do projeto.

PALAVRAS-CHAVE:Petrolina; Tecnologia cilindro-parabólico; Planta heliotérmica; Armazenamento de calor; Sistema Híbrido.

\section{ABSTRACT}

In Brazil, a region known as the northeastern semi-arid region has a high potential for the deployment of a heliothermic plant. One of the cities that are part of this region is Petrolina. In Petrolina, the implantation of a heliothermic plant of parabolic-cylinder technology can be seen as an attempt to insert and consolidate this technology in the Brazilian energy matrix. This work aims to model and simulate a hybrid heliothermic plant with heat storage in order to exploit the potential of solar energy irradiated in this region to transform it into electrical energy. Using the SAM software, the data of solar irradiation of Petrolina, obtained the simulation and the analysis of technical-economic results are obtained. Among the results obtained are the capacity factor of $77.5 \%$ and the generation of electric energy of 336,235,872.00 kWh, both data from the first year of the analysis. The methods of investment analysis used for the feasibility study were the internal rate of return and the net present value, both favorable to project implementation.

KEYWORDS: Petrolina; Cylinder-parabolic technology; Heliothermic plant; Heat storage; Hybrid System. 


\section{INTRODUÇÃO}

A tecnologia Concentrated Solar Power (CSP) apresenta resultados favoráveis em suas instalações espalhadas pelo mundo. Países como Estados Unidos e Espanha utilizam essa tecnologia principalmente para geração de energia elétrica e em processos industriais que necessitam de temperaturas elevadas. Essa tecnologia baseia-se na captação e conversão de energia solar em outra forma de energia, onde a mais utilizada é a conversão em energia elétrica.

Em 2017, embora a participação de renováveis na matriz energética brasileira manteve-se entre as mais elevadas do mundo, a contribuição da energia solar foi uma das menores, ficando apenas ao lado do gás industrial de carvão vegetal com $0,4 \%$ de contribuição cada [1]. Para buscar elevação dessa contribuição da energia solar e consequente da participação de renováveis no país, a inserção da tecnologia CSP ou energia heliotérmica na matriz energética brasileira é uma alternativa.

No Brasil, em uma região chamada de semiárido nordestino encontra-se a cidade de Petrolina. Essa cidade possui características favoráveis para instalação de uma planta heliotémica, pois apresenta elevados níveis de irradiação solar direta (DNI), infraestrutura, disponibilidade hídrica, entre outros [2].

As tecnologias de concentração solar utilizadas em grande escala são: Cilindro ou calha parabólica; essas são espelhos em forma de parábola que refletem os raios solares para um tubo receptor que fica localizado na linha focal da parábola. Ainda há: Torre Central, que são espelhos planos que refletem os raios solares para um receptor localizado em um ponto focal de uma torre; Disco Parabólico, composto por um disco em forma parabolóide com receptor localizado no foco do disco, onde está instalado um motor que opera no ciclo termodinâmico de Stirling; Concentrador Linear de Fresnel, são espelhos planos que refletem os raios solares para um receptor com foco linear. A figura 1 apresenta essas tecnologias na seguinte ordem da esquerda para direita e de cima para baixo: Torre Central, Calha Parabólica, Concentrador Linear de Fresnel e Disco Parabólico.

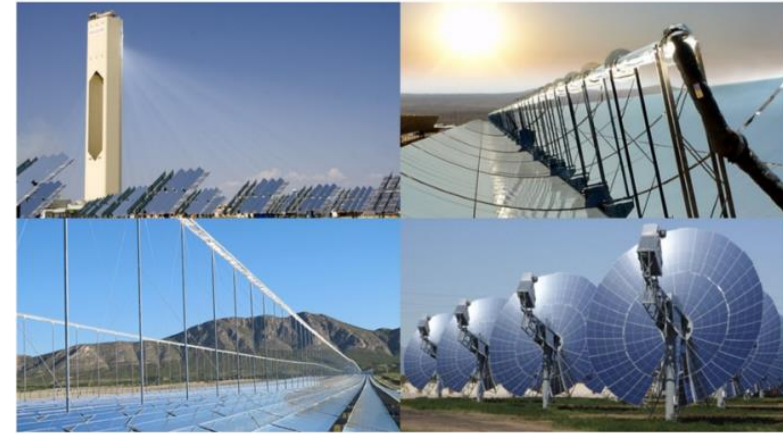

Figura 1:Tecnologias CSP.

Fonte: Adaptado [3].

\section{DESCRIÇÃO DE UMA PLANTA CILINDRO PARABÓLICO COM ARMAZENAMENTO DE CALOR E HIBRIDIZAÇÃO PARA GERAÇÃO DE ENERGIA ELÉTRICA}

Uma planta heliotérmica utilizada para geração de energia elétrica é composta por dois blocos: o campo solar e o de potência. No campo solar a energia é coletada, armazenada e fornecida ao fluido de transferência de calor (HTF). Esse fluido, ao passar por um trocador de calor, transportará a energia absorvida ao fluido de trabalho do bloco de potência. A hibridização é uma fonte de energia térmica oriunda de um recurso diferente da energia solar. Essa fonte pode ser renovável ou não. No bloco de potência é onde se converte a energia térmica em trabalho útil. A figura 2 apresenta uma ilustração de uma planta CSP híbrida e com armazenamento de calor.

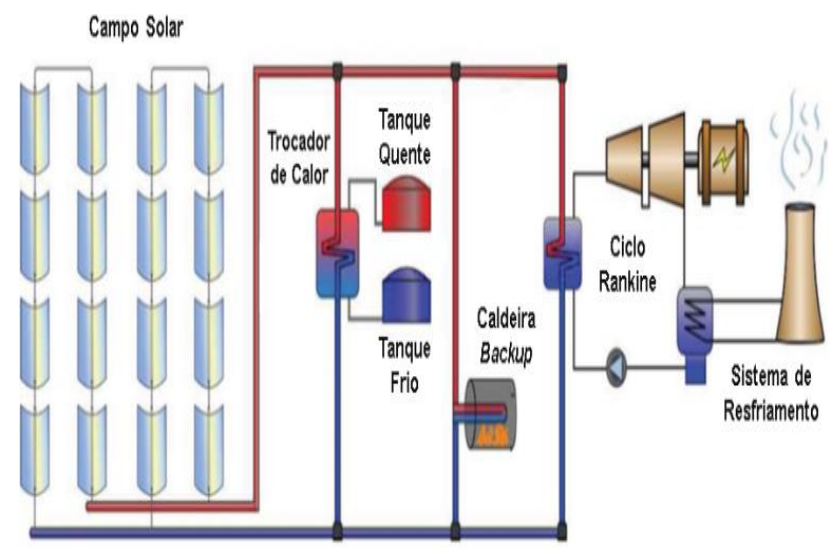

Figura 2: Planta CSP. Fonte: Adaptado [4]. 


\subsection{Campo solar}

O campo solar é responsável pela porção de calor da planta. Consiste em um ou mais conjuntos de ciclos de coletores solares, com cada ciclo disposto em paralelo. Um tubo de cabeçalho comum fornece a cada ciclo uma taxa de fluxo igual de fluido de transferência de calor (HTF), e um segundo cabeçalho coleta esse fluído quente para enviá-lo diretamente ao bloco de potência para geração de energia ou para o sistema de armazenamento de calor para uso posterior. Para minimizar as perdas de pressão de bombeamento, o campo solar é tipicamente dividido em várias seções, cada seção com seu próprio conjunto de cabeçalhos, e o bloco de potência fica situado próximo ao meio do campo. A figura 3 mostra um arranjo possível para planta em que duas seções de cabeçalhos são usadas para 20 ciclos [4]. Onde o campo é dividido em duas seções de cabeçalho. Cada ciclo na ilustração contém 8 conjuntos de coletores (SCAs) individuais, e cada parte do cabeçalho é conectado a dois ciclos, um na parte superior e outro na parte inferior da ilustração.

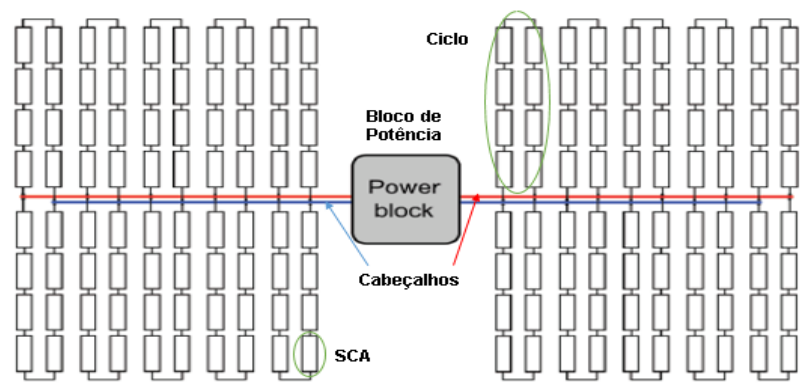

Figura 3: Arranjo de um campo solar.

Fonte: Adaptado [4].

As plantas heliotérmicas mais atuais incluem não apenas um campo solar e um bloco de potência, mas também um subsistema de armazenamento de térmico que pode ser projetado para despachar sua energia durante alguns minutos ou até um dia inteiro. Entre as energias renováveis, o CSP é único em possuir um sistema de armazenamento de energia térmica (TES) de forma econômica. O armazenamento permite a geração de energia elétrica durante oscilações na demanda, geralmente aumentando o fator de capacidade da planta ou fornecendo calor para outros subsistemas. Normalmente 0 subsistema é composto basicamente por dois tanques (chamados de tanque quente e tanque 23 frio), um trocador de calor e um meio de armazenamento (ex: sal fundido). Durante a operação da planta, a energia excedente a demanda do ciclo de potência é armazenada no tanque quente. Quando houver necessidade de calor adicional, o fluido de armazenamento que está no tanque quente começa a se transferir ao tanque frio passando através de um trocador de calor onde adicionará energia térmica ao fluido de transferência de calor (HTF) do campo solar aumentando assim sua temperatura até alcançar seu ponto de projeto.

Em algumas configurações de planta também incluem um sistema backup, uma caldeira para fornecer energia quando a fonte solar não está mais disponível ou não é suficiente. Por se tratar de uma contribuição de emergia não oriunda da energia solar dar-se o nome a planta de Sistema Híbrido. A caldeira pode operar em duas situações. Uma de caráter complementar quando adiciona energia térmica para contribuir com demanda necessária no bloco de potência. A outra de caráter suplementar quando fornece toda demanda de energia térmica ao bloco de potência. Essa última ocorrerá quando a energia solar não estiver mais disponível, ou seja, durante as horas sem sol e quando o armazenamento estiver esgotado. Nessa última configuração a planta trabalha exclusivamente queimando combustível da caldeira. Em ambas as situações o fornecimento de calor é para o fluido de transferência de calor (HTF) do campo solar.

Há caldeiras que operam com combustíveis fósseis (ex: gás natural) ou não fósseis (ex: biomassa) e que podem está localizada dentro ou fora do bloco de potência. A caldeira que opera utilizando como combustível a biomassa possui como característica a não agressão ao meio ambiente evitando a liberação de gases poluentes na atmosfera. Quanto à localização, altera o fluído que receberá o calor fornecido pela caldeira. Caso instalada no campo solar, o fluido HTF receberá esse calor. Caso contrário, o calor será fornecido diretamente ao fluido de trabalho do bloco de potência.

A figura 4 apresenta como exemplo uma planta com capacidade total de 40MW (sendo $30 \mathrm{MW}$ do bloco de potência e 10MW do TES) para demonstrar como se dá a contribuição de energia dos subsistemas durante as horas do dia. Nas primeiras e últimas horas do dia o sistema backup fornece energia necessária para manter a planta 
em operação. Quando os raios solares começam a ser coletados pelo campo, o que acontece ao amanhecer, o campo solar começa a contribuir com a demanda juntamente com o sistema backup até que consiga assumir inteiramente sozinho. Durante as horas de alta incidência dos raios solares a carga coletada pelo campo pode ser maior do que a suportada pelo bloco de potência. Quando isso acontece, essa energia excedente é direcionada para o sistema de armazenamento térmico (TES) e caso a energia exceda a capacidade do TES os espelhos do campo solar são desfocados para não coletar mais energia, promovendo a segurança da planta. Com o pôr do Sol, os raios solares tornam-se ausentes fazendo com que seja necessária a utilização da energia armazenada no TES.

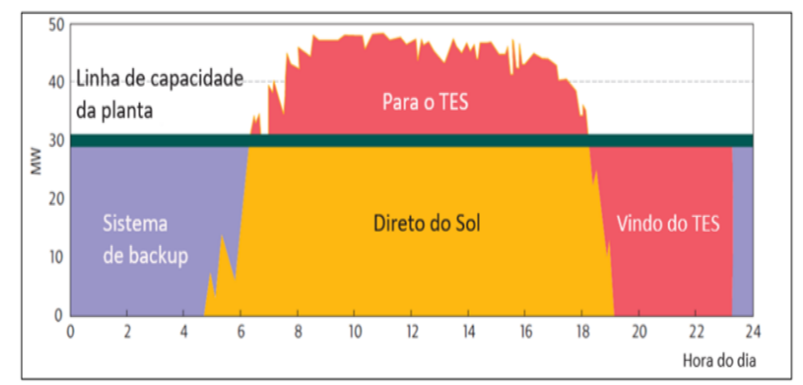

Figura 4: Curva demanda $x$ tempo.

Fonte: Adaptado [5].

\subsection{Bloco de potência}

O bloco de potência contém o equipamento necessário para converter energia térmica do campo solar em energia mecânica ou elétrica útil. Para sistemas CSP em escala de serviço público, envolve um ciclo Rankine a vapor convencional e um gerador elétrico, embora seja possível uma série de outras abordagens.

O ciclo Rankine a vapor convencional é composto por uma bomba de alimentação de água, um gerador de vapor, uma turbina a vapor e um condensador. A bomba envia a água em alta pressão ao gerador de vapor. O gerador de vapor nada mais é do que um trocador de calor que ao receber energia térmica de uma fonte quente ceda para a água transformando-a em vapor. A turbina recebe $o$ vapor com temperatura $e$ pressão elevadas. O vapor se expande dentro da turbina transformando sua energia térmica em energia mecânica. Essa energia é utilizada para girar um eixo que normalmente está conectado a um gerador elétrico. O vapor ao sair da turbina apresenta uma queda de pressão devido à expansão ocorrida. Esse vapor é direcionado a um trocador de calor chamado condensador, onde irá retornar a fase líquida através da troca de calor com o fluido do sistema de resfriamento. Já na fase líquida, a água é bombeada novamente ao gerador de vapor completando o ciclo. A figura 5 apresenta 0 ciclo Rankine convencional com condensação úmida e seus componentes.

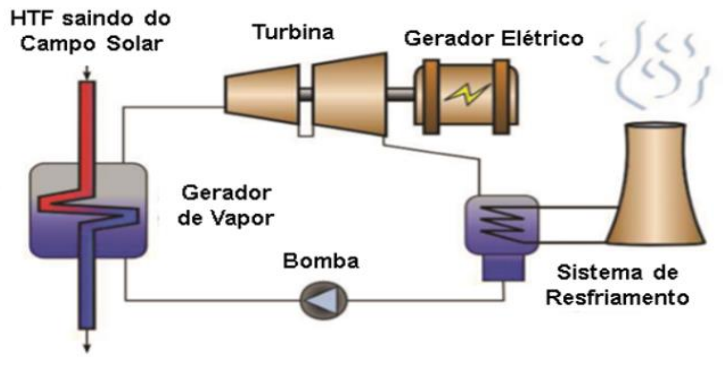

Figura 5: Ciclo Rankine a vapor Fonte: Adaptado [4].

\section{METODOLOGIA}

O projeto heliotérmico proposto é uma planta de tecnologia concentradores cilindro-parabólico (CSP), com armazenamento térmico de 6 horas e com uma caldeira backup utilizando gás natural como combustível.

Foi realizado um estudo básico de caráter quantitativo com objetivo de explorar as condições favoráveis da cidade de Petrolina para implantação de uma planta heliotérmica para geração de energia elétrica. Para tal finalidade é necessário buscar dados, propor parâmetros técnicos, modelar, simular e analisar resultados.

Este trabalho usa o Sytem Advisor Model (SAM), versão 2017.9.5, como principal ferramenta para buscar dados meteorológicos, modelar e simular a operação da usina. O software foi criado pela empresa americana National Renewable Energy Laboratory (NREL) [6].

O SAM é um modelo financeiro e de desempenho. O modelo financeiro calcula o fluxo de caixa anual durante o período desejado de acordo com as condições de custo e financiamento do projeto. $O$ modelo de desempenho calcula a operação e a geração elétrica de um ano típico em intervalos de uma hora, para um local pré-definido [4]. 
Dentro do modelo de desempenho, para a parte dos cálculos, o SAM utiliza o software TRNSYS, desenvolvido pela Universidade de Wisconsin, que consiste em um programa de simulação de série temporal que simula operações horárias de plantas fotovoltaicas, CSP, aquecimento de água e outras fontes renováveis [4].

\subsection{Dados meteorológicos}

Os dados meteorológicos de Petrolina foram obtidos através do SAM no mês de abril de 2017 e se refere a dados horários do ano de 2015. A biblioteca de recursos solares do SAM utiliza como fonte de dados, para localizações situadas no Brasil, o programa Avaliação de Recursos de Energia Solar e Eólica ou Assessment of Solar and Wind Energy Resources (SWERA)[6]. O SAM exibe informações e um resumo estatísticos dos dados para o arquivo que você escolheu. Ele calcula o resumo da insolação e os valores médios dos dados horários ou sub horários do arquivo meteorológico e os exibe para sua referência. Ele usa o arquivo de dados meteorológicos para a simulações em vez dos valores de resumo.Alguns dados horários obtidos são mostrados na tabela 1.

Tabela 1: Dados de Petrolina.

\begin{tabular}{c|c}
\hline Descrição & Valores \\
\hline Velocidade média do vento & $3,75 \mathrm{~m} / \mathrm{s}$ \\
\hline Temperatura média bulbo seco & $27,7^{\circ} \mathrm{C}$ \\
\hline Temperatura média bulbo úmido & $21^{\circ} \mathrm{C}$ \\
\hline DNI média & $875 \mathrm{~W} / \mathrm{m}^{2}$ \\
\hline
\end{tabular}

Fonte: SAM [6].

\subsection{Balanço de energia no campo solar}

Dentro de cada ciclo, um número de conjunto de coletores (SCAs) é usado para aquecer gradativamente o HTF até a temperatura de saída do projeto. Cada SCA é composto de um número de coletores parabólicos e seus receptores que compartilham um único drive de rastreamento comum. Cada conjunto é tratado como um nó independente dentro do ciclo, assim o balanço energético e outros valores de desempenho são calculados independente para cada um. Isso permite que cada SCA influencie separadamente o desempenho do ciclo [4].
Um modelo de receptor de estado estacionário típico determina a elevação de temperatura ( $\triangle T i)$ através do nó considerando a energia absorvida $\left(\dot{q}_{a b s}\right)$, a taxa de fluxo de massa de HTF através do receptor $\left(\dot{m}_{h t f}\right)$, e o calor específico do HTF $\left(c_{h t f}\right)$. As temperaturas de entrada e saída do nó $i$ são representadas respectivamente por $T_{\text {in }}$ e $T_{\text {out }}$ em Kelvin (K). Essa variação de temperatura para o nó $i$ é representado pela equação (1):

$$
\Delta T i=T_{o u t, i}-T_{i n, i}=\frac{\dot{q}_{a b s}}{\dot{m}_{h t f} c_{h t f}}
$$

No entanto, no caso da tecnologia de calha parabólica, a inércia térmica associada ao estado de energia do nó pode afetar o desempenho na medida em que um modelo de estado estacionário é insuficiente, termos assim transitórios devem ser incluídos. $O$ efeito transiente mais significativo no campo solar é a massa térmica do HTF nos cabeçalhos e na tubulação do receptor, portanto, precisamos considerar a mudança na energia do HTF na derivação das equações do balanço de energia [4]. A Figura 7 representa 0 balanço de energia para um volume de controle SCA.

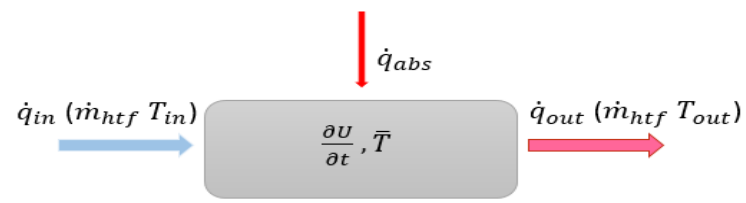

Figura 7: Volume de controle de um SCA.

Fonte: Os autores.

O balanço de energia acima mostra um tubo receptor com um fluxo de entrada $\left(\dot{q}_{i n}\right)$, fluxo de saída $\left(\dot{q}_{\text {out }}\right)$, energia absorvida $\left(\dot{q}_{a b s}\right)$ e um termo de energia interna $\left(\frac{\partial U}{\partial t}\right)$. Os fluxos de calor $(\dot{q})$ são funções da taxa de fluxo de massa do HTF $\left(\dot{m}_{h t f}\right)$, que é constante ao longo do SCA, e das temperaturas $T_{\text {in }}$ e $T_{\text {out }}$. A temperatura nodal média $(\bar{T})$ é igual à média das temperaturas de entrada e saída do nó, uma vez que o aumento da temperatura no nó é assumido como linear [4].

O termo energia interna $\frac{\partial U}{\partial t}$ representa a variação de energia em função do tempo $t$ para o nó. Assim, o balanço de energia total do volume de controle de um SCA é representado pela equação (2).

$$
\dot{q}_{\text {in }}+\dot{q}_{a b s}=\frac{\partial U}{\partial t}+\dot{q}_{o u t}
$$




\subsection{Balanço de energia no TES}

O SAM modela o armazenamento térmico para um sistema de dois tanques, ou seja, os dois tanques são capazes de armazenar todo o volume do fluido de armazenamento térmico. Um tanque é dedicado para armazenar o fluido quente, enquanto o outro mantém o fluido frio. A capacidade de armazenamento é expressa em horas equivalentes de carga total do TES. Isso significa que o número de horas de armazenamento fornece uma potência térmica necessária para que o bloco de potência opere em seu ponto de projeto.

A capacidade térmica do TES é igual a potência térmica requerida pelo bloco de potência em seu ponto de projeto $\left(\dot{W}_{\text {des }}\right)$ multiplicado pelo total de horas de armazenamento $\left(\Delta T_{\text {tes }}\right)$. A eficiência do ciclo $\left(\eta_{\text {cycle,des }}\right)$ é constante e especificado pelo projeto. Assim a capacidade térmica do TES em Watts é representada pela equação (3).

$$
E_{\text {tes }}=\frac{\dot{W}_{\text {des }} \Delta T_{\text {tes }}}{\eta_{\text {cycle }, \text { des }}}
$$

Tomando um taque de armazenamento térmico como volume de controle podemos estabelecer, através da primeira lei da termodinâmica, a equação do balanço de energia. A figura 8 representa um volume de controle para um tanque do TES.

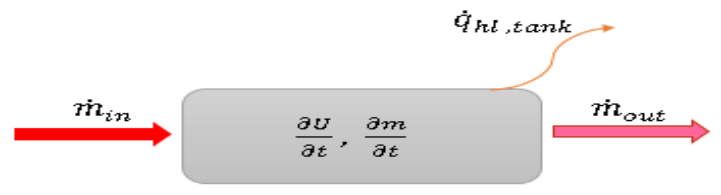

Figura 7: Volume de controle do Tanque do TES.

Fonte: Os autores.

O volume do fluido de um tanque de armazenamento varia de acordo com a diferença da taxa do fluxo de massa da entrada $\left(\dot{m}_{\text {in }}\right)$ e saída $\left(\dot{m}_{\text {out }}\right)$. A massa final em quilogramas de fluido de armazenamento dentro do tanque após um intervalo de tempo $(\Delta T)$ é representado pela equação (4).

$$
m_{f i n}=m_{0}+\Delta T\left(\dot{m}_{\text {in }}-\dot{m}_{\text {out }}\right)
$$

O balanço de energia no volume de controle do tanque é dado pela equação (5). Os temos de energia interna $\left(\frac{\partial U}{\partial t}\right)$, massa $\left(\frac{\partial m}{\partial t}\right)$ e perda de 26 calor do tanque $\left(\dot{q}_{h l, t a n k}\right)$ são todas funções do tempo. A temperatura de saída $T$ é a média do tanque.

$$
\begin{gathered}
\frac{\partial((u(t) m(t))}{\partial t}= \\
-\dot{q}_{h l, \text { tank }}(t)+\dot{m}_{\text {in }} h\left(T_{\text {in }}\right)-\dot{m}_{\text {out }} h(T(t))
\end{gathered}
$$

\subsection{Caldeira backup}

O SAM modela uma aquecedor auxiliar ou caldeira backup para queimar combustível fóssil gerando calor para geração de energia elétrica. Possui sua taxa de aquecimento limitado a entrada térmica do bloco de potência. A temperatura ajustada para o aquecimento do HTF ( $\left.T_{\text {aux }, \text { set }}\right)$ é especificada pelo projeto. Já a temperatura em que o HTF deve sair do aquecedor $\left(T_{\text {aux }, \text { out }}\right)$, em Kelvin (K), é alcançada em função da mínima temperatura nominal ou usando a taxa máxima de aquecimento, conforme mostrada na equação (6).

$$
T_{\text {aux }, \text { out }}=\min \left[T_{\text {aux }, \text { set }}, T_{\text {aux }, \text { in }}+\frac{\dot{q}_{\text {aux } \text { max }}}{\dot{m}_{\text {aux }, \text { htf }} c_{\text {aux }, \text { htf }}}\right]
$$

O calor específico do HTF ( $\left.c_{\text {aux }, h t f}\right)$ é especificado na temperatura de entrada do aquecedor $\left(T_{\text {aux,in }}\right)$. A transferência total de energia térmica para o HTF é proporcional ao seu aumento de temperatura alcançado. A equação (7) representa a taxa de transferência de calor $\left(\dot{q}_{\text {aux }}\right)$, em Watts $(\mathrm{W})$, do aquecedor auxiliar ao HTF.

$$
\dot{q}_{a u x}=\dot{m}_{a u x, h t f} c_{h t f}\left(T_{a u x, o u t}-T_{a u x, \text { in }}\right)
$$

O uso do combustível é uma métrica importante para o desempenho do aquecedor. $\mathrm{O}$ valor energético do combustível é medido na unidade de milhões de BTU (MMBTU). O SAM considera que não há perdas térmicas do aquecedor e utiliza a eficiência de baixo valor de aquecimento ( $\left.\eta_{L H V}\right)$ para estimar 0 teor energético do combustível ( $\left.E_{f u e l}\right)$. A equação (8) representa o teor energético do combustível em Joules (J).

$$
E_{\text {fuel }}=\frac{\dot{q}_{\text {aux }}}{\eta_{L H V}} \Delta t \times\left[3.412 \times 10^{-6} \frac{M M B T U}{W h r}\right]
$$




\subsection{Entradas para o campo solar}

As entradas para o campo solar são equipamentos ou valores especificados para realização do projeto. A metodologia para propor os parâmetros de projeto se deu através de simulações prévias no próprio SAM, utilizando sua biblioteca como fonte de dados. O quadro 1 apresenta os dados de entrada para o campo solar.

Quadro 1: Condições de projeto do campo solar.

\begin{tabular}{|c|c|}
\hline Itens & Entradas \\
\hline Múltiplo Solar & 2 \\
\hline $\begin{array}{l}\text { Irradiação direta normal } \\
\text { para o projeto }\end{array}$ & $875 \mathrm{~W} / \mathrm{m}^{2}$ \\
\hline $\begin{array}{c}\text { Fluido de transferência } \\
\text { de calor (HTF) }\end{array}$ & Therminol VP-1 \\
\hline $\begin{array}{c}\text { Temperatura do HTF } \\
\text { na entrada do ciclo }\end{array}$ & $293^{\circ} \mathrm{C}$ \\
\hline $\begin{array}{c}\text { Temperatura do HTF } \\
\text { na saída do ciclo }\end{array}$ & $391^{\circ} \mathrm{C}$ \\
\hline Orientação Coletor & $\begin{array}{l}\text { Tilt }=10^{\circ} \\
\text { Azimute }=0^{\circ}\end{array}$ \\
\hline Coletor & $\begin{array}{c}\text { SkyFuel SkyTrough } \\
\text { (with 80-mm OD receiver) }\end{array}$ \\
\hline Receptor & Schott PTR80 \\
\hline Armazenamento de calor & $6 \mathrm{~h}$ \\
\hline $\begin{array}{l}\text { Fluido de armazenamento } \\
\text { de calor }\end{array}$ & Hitec Solar Salt \\
\hline Sistema de Hibridização & Operação suplementar \\
\hline Combustível caldeira back-up & Gás natural \\
\hline $\begin{array}{l}\text { Pressão de operação da } \\
\text { caldeira back-up }\end{array}$ & 80 Bar \\
\hline $\begin{array}{c}\text { Eficiência LHV da caldeira } \\
\text { back-up }\left(\eta_{L H V}\right)\end{array}$ & $90 \%$ \\
\hline
\end{tabular}

Fonte: Os autores.

\subsection{Ciclo Rankine a vapor}

O SAM modela o bloco de potência utilizando um ciclo Rankine a vapor contem no seu volume de controle diversos componentes como turbina, condensador, bomba de condensado, bomba de água de alimentação, desvairador, aquecedor de água de alimentação, permutador de calor de préaquecimento, caldeira, permutador de calor de superaquecimento e permutador de calor de reaquecimento. Uma problemática para modelagem desse volume de controle é opção de escolher entre a condensação a ar ou úmida. Essa opção faz com que o bloco de potência possua dificuldades para manipular os dois tipos de fluxo. Assim, para efeitos de cálculo do volume de controle, o SAM despreza a corrente do fluido de resfriamento (ar ou água) que passa dentro do condensador e mantém apenas o fluxo de vapor no cálculo.

O objetivo da modelagem do bloco de potência é caracterizar com precisão o desempenho fora das condições de projeto, proporcionando flexibilidade suficiente para lidar com os projetos típicos do ciclo Rankine a vapor. O SAM utiliza o software Engineering Equation Solver (EES)para realizar a simulação de processo e construir um ciclo detalhado representativo, em vez de incorporar um modelo detalhado diretamente no TRNSYS.

O modelo representativo é um ciclo Rankine básico de 10MWe. A partir dele é analisado o comportamento do desempenho do ciclo fora das condições de projeto. São variáveis utilizadas como entradas que podem causar alteração nas condições de projeto: a temperatura de vapor na entrada da turbina, eficiência isentrópica da bomba de alimentação de água, pressão da caldeira e outras. Embora o modelo representativo seja referente a um ciclo de $10 \mathrm{MWe}$, o comportamento exibido por ele, fora das condições de projeto, aplica-se a qualquer nível de potência [4].

O método de análise do comportamento do desempenho fora das condições de projeto utilizado pelo SAM é o chamado de modelo da regressão. Um procedimento para desenvolver um modelo de regressão a partir de cálculos de desempenhos mais detalhados é resumido da seguinte forma [4]:

- Limites práticos sobre o intervalo das três variáveis independentes são identificados. As variáveis são temperatura de entrada do HTF, pressão de condensador e taxa de fluxo de massa do HTF.

- As execuções paramétricas avaliam potência de saída e ciclo de absorção de calor em toda a gama de entradas.

- As informações geradas por execuções paramétricas em software de modelagem detalhada não são dimensionáveis.

- A informação não dimensional é analisada para determinar os principais efeitos e interações.

- Esses efeitos são consolidados e aplicados no código.

Já que o modelo de regressão utiliza a potência de saída e a entrada de calor como funções da temperatura do HTF, da pressão do 
condensador e da taxa de fluxo de massa, o modelo usa outro conjunto de equações para calcular outros valores de desempenho. O cálculo da eficiência do bloco de potência $\left(\eta_{\text {cycle }}\right)$ é simples. A eficiência do ciclo de potência termodinâmica é determinada simplesmente dividindo a saída de trabalho $(\dot{W})$ pela entrada de calor $(\dot{Q})$ necessária, veja na equação (9).

$$
\eta_{\text {cycle }}=\frac{\dot{W}}{\dot{Q}}
$$

A temperatura de saída do HTF $\left(T_{h t f, o u t}\right)$ do bloco de potência é calculada considerando-se a taxa de fluxo de massa do HTF ( $\left.\dot{m}_{h t f}\right)$, a entrada de calor $(\dot{Q})$, a temperatura de entrada $\left(T_{h t f, i n}\right)$ e o calor específico do HTF. Presume-se que o calor específico varie linearmente ao longo do intervalo das temperaturas de entrada e saída. Assim, um valor de calor específico ( $c_{k t f, a v e}$ ) é usado e é recalculado ao longo da simulação. A equação (10) representa a temperatura de saída do HTF em Kelvin (K).

$$
T_{h t f, \text { out }}=T_{h t f, \text { in }}-\frac{\dot{Q}}{\dot{m}_{h t f} c_{k t f, a v e}}
$$

O modelo do ciclo Rankine não inclui diretamente o condensador no volume de controle. Em vez disso, ele fornece informações para um modelo externo de rejeição de calor sobre a magnitude da carga de rejeição. Este valor é igual à diferença entre a saída do trabalho e a absorção de calor $(\dot{Q})$, ou pela na equação (11). A taxa de calor rejeitado no condensador $\left(\dot{q}_{r e j}\right)$ é expresso em Watts (W).

$$
\dot{q}_{r e j}=\left(1-\eta_{c y c l e}\right) \dot{Q}
$$

Minerais, incrustações e outros sólidos se acumulam na caldeira durante a operação. 0 acúmulo excessivo dessas partículas prejudica o desempenho do trocador de calor e pode danificar turbinas e bombas. Essa situação é evitada extraindo-se uma fração do fluxo de vapor e substituindo-a por uma nova fração de água desmineralizada. Água e vapor são perdidos através de outros mecanismos, incluindo vazamentos no circuito de fluxo pressurizado, arrastamento de vapor com não-condensáveis no processo de purga e evaporação do sistema de resfriamento úmido. Todas essas perdas de água devem ser repostas para manter fluxo constante 28 na planta. O SAM modela a taxa de reposição de água (excluindo a evaporação causada pela condensação úmida) calculando uma taxa de fluxo de massa de vapor aproximada durante a operação e a reposição de uma fração fixa de água [4].

A taxa do fluxo de massa da purga do vapor $\left(\dot{m}_{s t, b d}\right)$ é calculada pela Equação (12) e dada em quilogramas por segundo $(\mathrm{kg} / \mathrm{s})$, onde a fração de purga é dada por $f_{b d}$ e a entalpia total de adição de calor através dos permutadores de calor é $\Delta h_{\text {heat. }}$

$$
\dot{m}_{s t, b d}=\frac{\dot{W} f_{b d}}{\eta_{c y c l e} \Delta h_{\text {heat }}}
$$

O modelo assume uma fração de purga padrão de 2,0\%, mas essa fração pode ser ajustada para cada projeto. A variação de entalpia $\left(\Delta h_{\text {heat }}\right)$ entre os trocadores de calor é estimada assumindo que a queda da temperatura do HTF quente é de $25^{\circ} \mathrm{C}$, após ceder calor ao vapor de entrada da turbina, e assumindo que a temperatura da água de alimentação na entrada do pré-aquecedor é de $100^{\circ} \mathrm{C}$, valor abaixo da temperatura de ebulição para a pressão de 100 bar [4].

\subsection{Entradas para o bloco de potência}

Os valores de entrada para as condições de projeto do bloco de potência foram determinados utilizando a biblioteca do SAM. Para o modelo da turbina e a eficiência termodinâmica do ciclo, a capacidade da planta foi utilizada como referência. Já em relação ao sistema de resfriamento, a disponibilidade hídrica da região foi o determinante. 0 quadro 2 apresenta as entradas para o bloco de potência.

Quadro 2: Condições de projeto do bloco de potência.

\begin{tabular}{|c|c|}
\hline Itens & Entradas \\
\hline Capacidade da Planta & Somwe \\
\hline Turbina & Fixa \\
\hline $\begin{array}{c}\text { Pressão na entrada da } \\
\text { turbina }\end{array}$ & $37,36 \%$ \\
\hline $\begin{array}{c}\text { Eficiência de conversão do } \\
\text { ciclo termodinâmico }\end{array}$ & Evaporativo (úmido) \\
\hline Tipo de condensador & 1,25 inHg \\
\hline Pressão de condensação & $2 \%$ \\
\hline Fração da purga & \\
\hline
\end{tabular}

Fonte: Os autores. 


\subsection{Parâmetros financeiros}

Os valores utilizados para o modelo financeiro foram obtidos da biblioteca do SAM. Esses valores refletem a melhor estimativa National Renewable Energy Laboratory (NREL) sobre os custos representativos dos sistemas CSP nos Estados Unidos no momento do lançamento desta versão do SAM [6].

O SAM disponibiliza vários modelos financeiros para elaboração de um projeto, entre eles há o PPA Single Owner. Nesse modelo, o SAM calcula o preço PPA como o preço que o projeto recebe por cada unidade de eletricidade gerada pelo sistema. Utiliza-se como base uma taxa interna de retorno requerida (TIR) pelo projeto. A TIR é uma medida de rentabilidade do projeto. Além de especificar a TIR, o modelo permite determinar 0 ano, do período de análise, que ela deve ser atingida [6].

O período de análise do projeto foi proposto de maneira arbitrária, tendo em vista que a tecnologia CSP para geração de energia elétrica, em escala de serviço público, não faz parte da matriz energética brasileira. Sendo assim, ainda não possui legislação específica.

A tabela 2 apresenta os valores de entrada para o projeto financeiro.

Tabela 2: Parâmetros financeiros utilizados como entradas no SAM.

\begin{tabular}{c|c}
\hline Itens & Entradas \\
\hline Período de análise & 30 anos \\
\hline Custo total instalado & $\$ 298.826 .176,00$ \\
\hline $\begin{array}{c}\text { Taxa real de desconto } \\
\text { (a.a.) }\end{array}$ & $5,5 \%$ \\
\hline Tributo federal (a.a.) & $28 \%$ \\
\hline Tributo Estadual (a.a.) & $7 \%$ \\
\hline Seguro & $0,5 \%$ do custo total instalado \\
\hline Valor residual líquido & $0,0 \%$ do custo total instalado \\
\hline Prazo de amortização & $7 \%$ \\
\hline Taxa de juros (a.a.) & $100 \%$ \\
\hline Fração da dívida & $11 \%$ \\
\hline TIR requerida (a.a.) & $4 \%$ \\
\hline Taxa de degradação (a.a.) & líquido \\
\hline Depreciação (a.a.) & $2,5 \%$ do custo de \\
\hline
\end{tabular}

Fonte: Os autores

\section{RESULTADO}

O SAM é baseado em uma simulação de segurança que interage com o desempenho, o custo e o modelo financeiro para calcular a saída de energia e o fluxo de caixa. A maioria das entradas podem ser usadas como variáveis paramétricas para estudos de sensibilidade e investigar os impactos das variações no desempenho, custo e resultados financeiros dos modelos [6].

\subsection{Resultados financeiros}

As métricas financeiras analisados pelo SAM dependem do modelo financeiro adotado. Para o projeto proposto é utilizado o modelo PPA Single Owner. O modo de solução especifica uma taxa interna de retorno (TIR) de $11 \%$ para ser atingida em 20 anos, e com essas condições do projeto requeridas, calcular o preço PPA para venda de energia gerada pela planta. O SAM usa um algoritmo interativo para pesquisar o preço PPA que atenda a meta da TIR no ano especificado.

As figuras 8 e 9 mostram, respectivamente, o comportamento da TIR em \% e do preço PPA em $\$ / k W h$, durante $o$ período de análise do projeto. A TIR requerida de $11 \%$ é alcançada no ano 20 , como especificado pelo projeto No final do período de análise a taxa de rentabilidade chaga $11,62 \%$. O preço PPA de energia apresenta uma elevação durante os anos devido a aplicação da taxa de escalonamento de $1 \%$ ao ano especificada no projeto. Essa taxa é aplicada a partir do segundo ano do fluxo de caixa tomando como base para o cálculo o preço PPA do ano 1 .

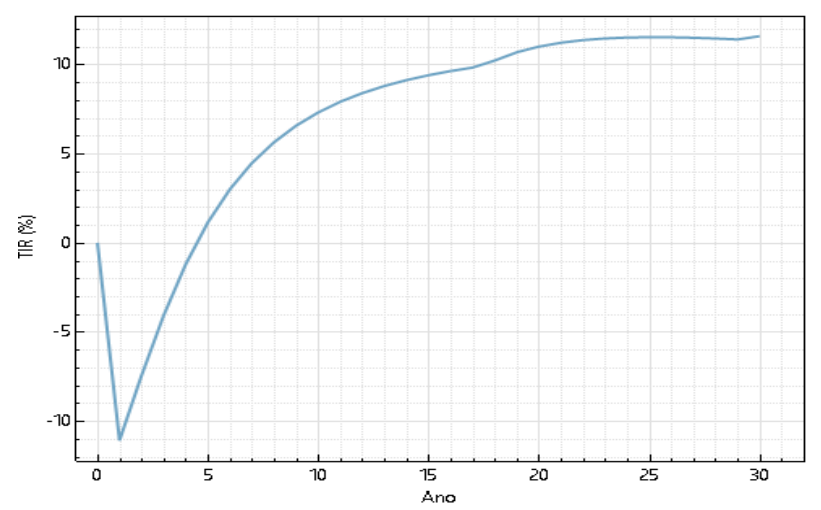

Figura 8: TIR durante do projeto.

Fonte: Os autores 


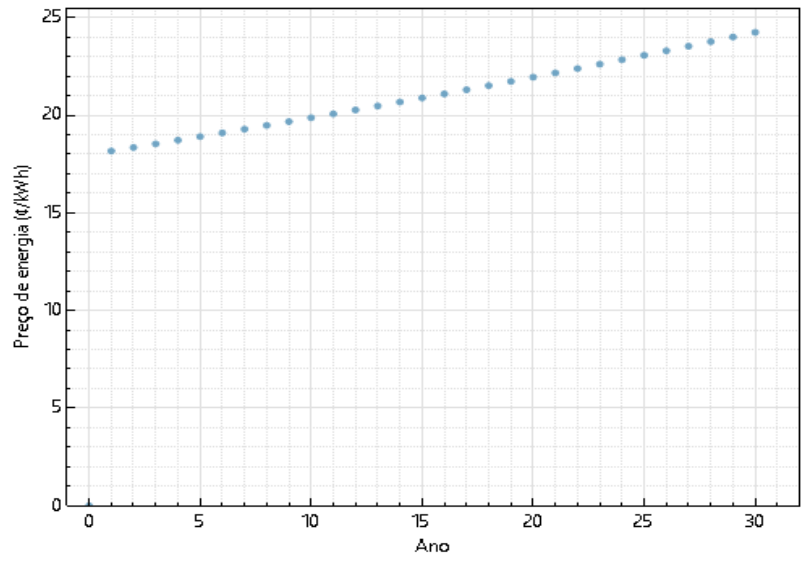

Figura 9: Preço PPA durante do projeto.

Fonte: Os autores

Além da TIR, o SAM disponibiliza o valor presente líquido (VPL) como método de análise para investimento. Esse método é capaz de determinar o valor presente de pagamentos futuros descontados a uma taxa de juros apropriada, menos o custo do investimento inicial. A figura 10 representa o VPL do projeto durante 0 período de análise.

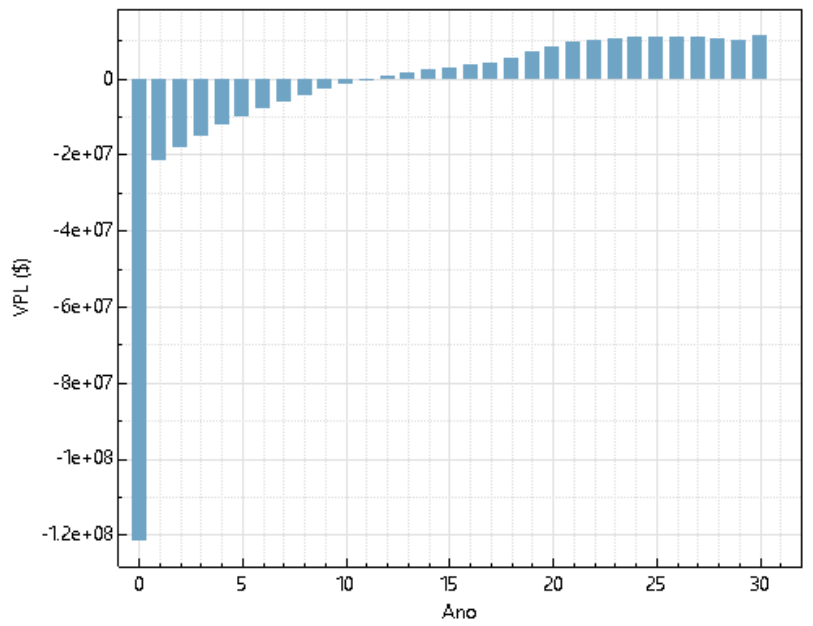

Figura 10:VPL durante do projeto.

Fonte: Os autores

É importante observar que o período ente os anos 11 e 12 na figura 10 representa uma outra ferramenta para critérios de decisão de investimento que é o payback descontado ou período de retorno descontado. O payback descontado é o tempo necessário para que o projeto se pague, ou seja, tempo necessário para que a soma dos fluxos seja positiva. O payback descontado utiliza o fluxo de caixa descontado da taxa de desconto anual.

\subsection{Resultados de desempenho}

As métricas de desempenho são valores calculados pelo SAM a partir dos resultados do modelo de desempenho por hora. O modelo proposto é do CSP calha parabólico física ou Parabolic Trough (Physical).

O SAM informa a quantidade total de energia elétrica gerada pelo sistema no primeiro ano do fluxo de caixa do projeto. O SAM pressupõe que toda eletricidade é vendida ao preço PPA.

A energia anual é igual a somo de toda energia elétrica gerada horária entregue a rede durante um ano. A figura11 apresenta a distribuição mensal da energia anual gerada durante o período de análise do projeto.

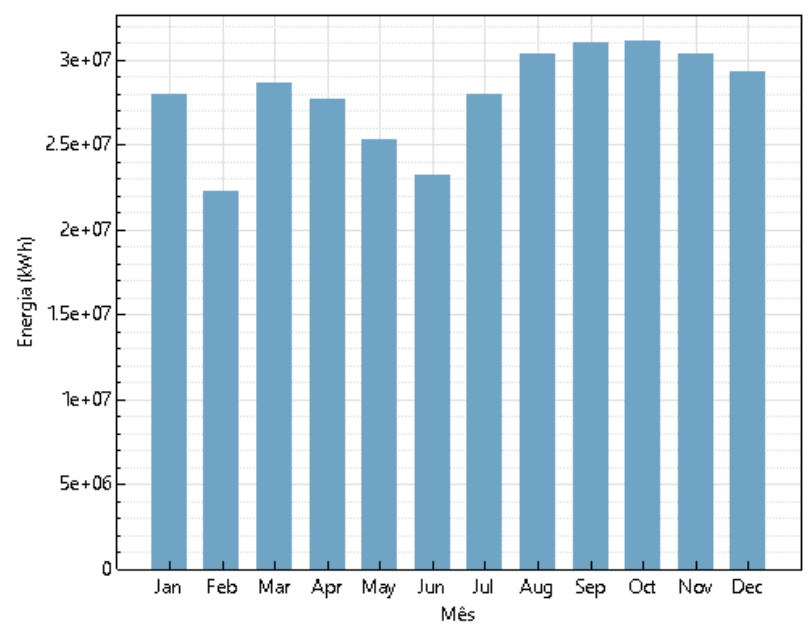

Figura 11: Geração de eletricidade durante o projeto. Fonte: Os autores.

É possível notar uma queda na geração de energia no mês de fevereiro, causado pelo número de dias do mês. O SAM considera fevereiro com 28 dias. Entre os meses de maio e julho houve uma queda na geração de eletricidade causada por uma falha no controle de despacho do armazenamento térmico e do aquecedor auxiliar (caldeira backup). O controle manteve a mesma configuração em uma faixa horária de despacho durante todo o ano, não admitindo variações meteorológicas, como poucas horas de Sol diárias e alta intensidade de nuvens, causadas pelas mudanças das estações do ano, conforme mostrado na figura 12 . 


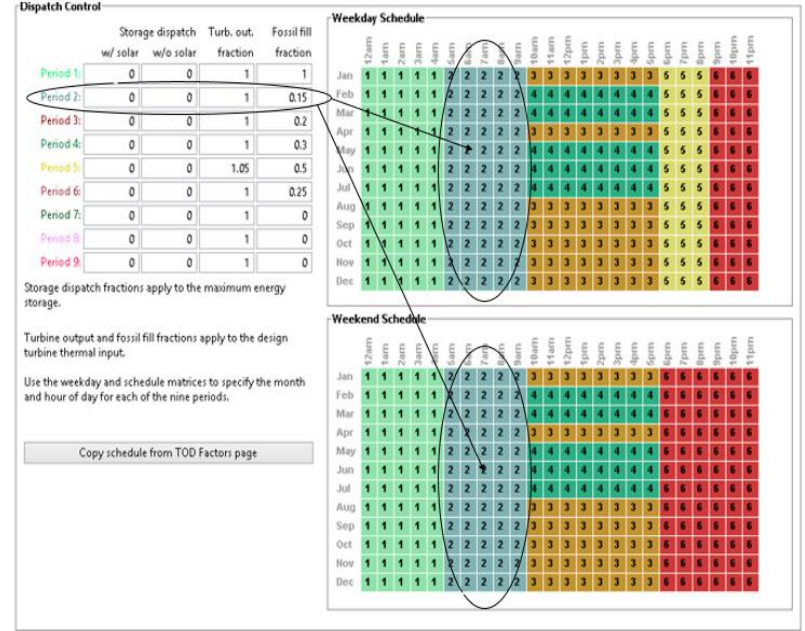

Figura 12: Controle de despacho do SAM.

Fonte: Adaptado [6].

A potência térmica fornecida ao bloco de potência e sua composição da energia em relação a fonte estão representadas nas figuras 13 e 14, respectivamente.

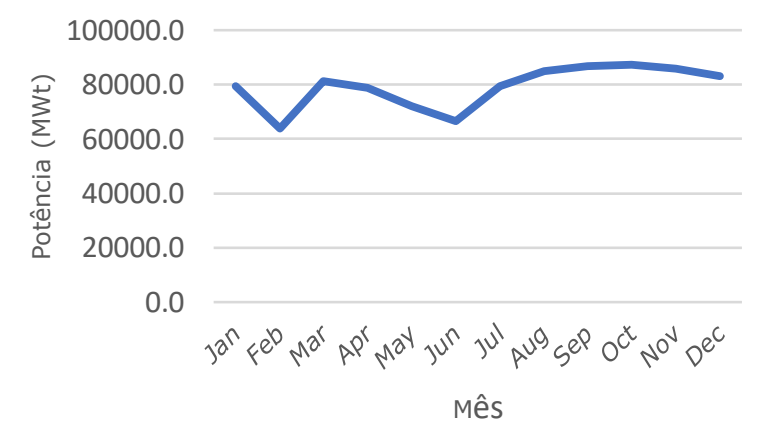

Figura 13: Potência térmica produzida.

Fonte: Os autores.

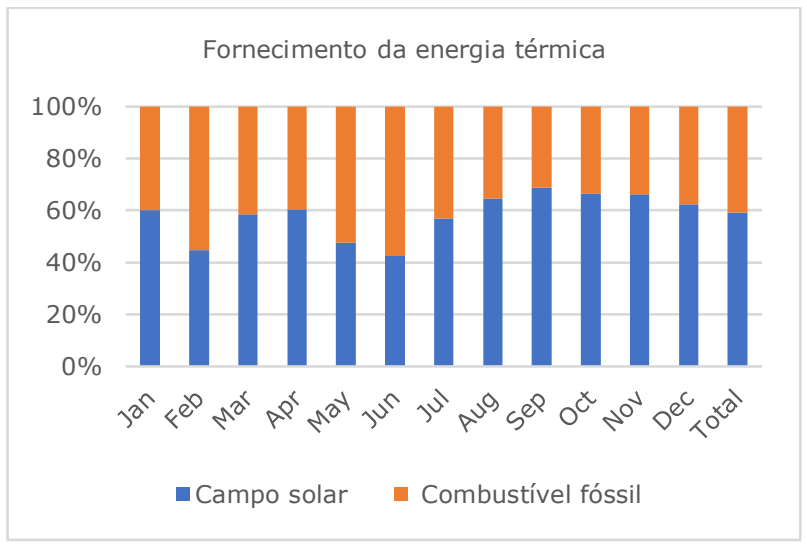

Figura 14: Composição da potência térmica.

Fonte: Os autores.
Observado nas figuras 13 e 14 a mesma característica de queda durante o ano devido ao controle de despacho ineficiente. A potência térmica sofre influência direta da falta raios solares. A caldeira backup não forneceu a energia térmica suficiente para manter a potência de projeto porque o controle de despacho não estava adequado.

Outros resultados obtidos são mostrados no quadro 3.

\begin{tabular}{|c|c|}
\hline Itens & Valores \\
\hline Energia elétrica anual (ano 1) & $336.235 .872,00 \mathrm{kWh}$ \\
\hline Fator de conversão & $94 \%$ \\
\hline Fator de Capacidade (ano 1) & $77,5 \%$ \\
\hline Consumo anual de água & $1.219 .877,00 \mathrm{~m}^{3}$ \\
\hline Preço de energia (ano 1) & $18,20 \$ / \mathrm{kWh}$ \\
\hline Custo nivelado de energia & $19,13 \$ / \mathrm{kWh}$ \\
\hline Preço nivelado de energia & $19,57 \$ / \mathrm{kWh}$ \\
\hline Valor presente líquido (VPL) & $\$ 11.928 .845,00$ \\
\hline TIR ao fim do projeto & $11,62 \%$ \\
\hline Ano em que é alcançado a \\
TIR requerida
\end{tabular}

Quadro 3: Resultados financeiros e desempenho.

Fonte: Os autores.

\section{CONCLUSÕES}

Os números apresentados da geração de energia elétrica e do fator de capacidade nos deixam otimistas para uma possível implantação da usina. A hibridização e o armazenamento de calor são fundamentais para operação da usina durante as horas sem Sol (período noturno). Aumentar a capacidade do sistema de armazenamento de calor e configurar o controle de despacho de maneira otimizada deve permitir elevar o fator de capacidade da planta e consequentemente diminuir sua dependência da queima do combustível fóssil. A utilização de 
combustíveis não fósseis na caldeira back-up seria de extrema importância para evitar a emissão de gases poluentes na atmosfera.

Para o estudo de viabilidade econômica foram utilizados dois métodos, a TIR e o VPL. Embora a TIR e o VPL tenham se mostradas favoráveis ao investimento, é interessante aplicar outros métodos de análises mais avançados. Comparar com outros tipos de projetos na área de geração de energia elétrica, com fontes de energia renovável, pode servir de grande utilidade para análise de viabilidade do investimento.

\section{REFERÊNCIAS}

[1] EMPRESA DE PESQUISA ENERGÉTICA (EPE). Balanço Energético Nacional 2018, Relatório síntese ano base 2017. Rio de Janeiro, maio 2018. Disponível em: http://www.epe.gov.br/sites-pt/publicacoesdadosabertos/publicacoes/PublicacoesArquivos/publ icacao-303/topico-397/Relatório Síntese 2018-ab 2017 vff.pf. Acesso em: 24 ago. 2018.

[2] GUIMARÃ̃ES, A. P. C. et al. Caracterização de localidades do semi-árido para implantação de um sistema piloto heliotérmico de geração elétrica. In: CONGRESSO BRASILEIRO DE ENERGIA SOLAR, 3., set. 2010, Belém. Anais [...] Porto Alegre: ABENS, 2010.

[3] COSTA, D. L. C.; NETO, J. H. M. Uma análise tecno-econômica de uma CSP Torre Central no Chile com diferentes níveis de armazenamento de energia e Hibridização. In: CONGRESSO BRASILEIRO DE ENERGIA SOLAR, 7., abr. 2018, Gramado. Anais [...] Porto Alegre: ABENS, 2018.

[4] WAGNER, M. J.; GILMAN, P. Technical Manual for the SAM Physical Trough Model. Techinal report NREL/TP-5500-51825. Colorado: NREL, June 2011. Disponível em: https://www.nrel.gov/docs/fy110sti/518 25.pdf. Acesso em: 07 jul. 2018.

[5] GIL, A. et al. State of the art on high temperature thermal energy storage for power generation. Part 1-Concepts, materials and modellization. Renewable and Sustainable Energy Reviews, v. 14, n. 1, p. 31-55, 2010.

[6] NATIONAL RENEWABLE ENERGY LABORATORY (NREL). Manual SAM versão 2017.1.17. Colorado: NREL, Nov. 2018.
Disponível em: https://sam.nrel.gov/download. Acesso em: 23 set. 2017. 